\title{
Avaliação da presença de células caliciformes na córnea humana
}

\author{
Evaluation of the presence of goblet cells on the human corneal surface
}

\author{
Jeison de Nadai Barros ${ }^{1}$ \\ Vera Lucia Degaspare Mascaro ${ }^{2}$ \\ José Álvaro Pereira Gomes ${ }^{3}$ \\ Luciene Barbosa de Sousa ${ }^{4}$ \\ Ana Luisa Hofling-Lima ${ }^{5}$
}

Trabalho realizado no Departamento de Oftalmologia da Universidade Federal de São Paulo - UNIFESP.

'Tecnólogo Oftálmico do Laboratório de Doenças Externas Oculares da Universidade Federal de São Paulo - UNIFESP.

2 Encarregada do Setor de Córnea e Doenças Externas do Hospital do Servidor Público Estadual I.A.M.S.P.E FMO e Colaboradora nos Setores de Patologia Externa e Córnea e no Laboratório de Doenças Externas Oculares da Universidade Federal de São Paulo - UNIFESP. ${ }^{3}$ Doutor em Oftalmologia, Colaborador do Setor de Patologia Externa e Córnea da Universidade Federal de São Paulo - UNIFESP.

${ }^{4}$ Doutora em Oftalmologia, Chefe do Setor de Patologia Externa e Córnea da Universidade Federal de São Paulo - UNIFESP.

${ }^{5}$ Livre-docente, Chefe do Departamento de Oftalmologia e do Laboratório de Doenças Externas Oculares da Universidade Federal de São Paulo - UNIFESP.

Endereço para correspondência: Jeison de Nadai Barros, Rua Itapeva, 56/101 - São Paulo (SP) CEP 01332-000 E-mail: jbarros@oftalmo.epm.br

Recebido para publicação em 05.12.2002

Versão revisada recebida em 08.05.2003

Aprovação em 09.05.2003

Nota Editorial: Pela análise deste trabalho e por sua anuência na divulgação desta nota, agradecemos aos Drs. João Orlando Ribeiro Gonçalves e João Agostini Neto.

\begin{tabular}{|l|}
\hline RESUMO \\
\hline Objetivo: Analisar pela citologia de impressão a presença de células cali- \\
ciformes na superfície de córneas com sinais clínicos de conjuntivalização. \\
Métodos: Foram realizados exames de citologia de impressão do epitélio \\
córneo-conjuntival em 65 olhos de 65 pacientes com sinais clínicos de \\
conjuntivalização com ou sem tratamento cirúrgico prévio. Os pacientes \\
foram divididos em dois grupos segundo a história anterior de cirurgia de \\
reconstrução da superfície ocular com transplante de limbo e membrana \\
amniótica de tal forma que no grupo I foram estudados 49 pacientes sem \\
cirurgia prévia e no grupo II estudaram-se 16 pacientes após cirurgia para \\
reconstrução da superfície e com sinais de conjuntivalização recorrente. \\
As amostras foram colhidas do olho afetado entre fevereiro de 2000 e \\
fevereiro de 2002 no Laboratório de Doenças Externas Oculares do Departa- \\
mento de Oftalmologia da UNIFESP. Definiu-se que o diagnóstico de \\
deficiência límbica era confirmado por citologia de impressão quando uma \\
ou mais células caliciformes íntegras eram encontradas na superfície da \\
córnea. Resultados: No grupo I uma ou mais células caliciformes foram \\
evidenciadas na superfície da córnea em 21 olhos (42,85\%). No grupo II foi \\
possível detectá-las na superfície da córnea em 9 pacientes (56,25\%). \\
Conclusão: A presença de células caliciformes na superfície da córnea \\
detectada no exame de citologia de impressão em pacientes com conjun- \\
tivalização pode confirmar o diagnóstico de deficiência de limbo no local \\
pesquisado, porém, a ausência destas células não exclui o diagnóstico. \\
\hline
\end{tabular}

Descritores: Limbo da córnea/citologia; Conjuntiva/citologia; Células caliciformes; Células epiteliais; Neovascularização patológica/patologia; Técnicas citológicas; Técnicas de diagnóstico oftalmológico

\section{INTRODUÇÃO}

Evidências recentes indicam que uma fração das células epiteliais basais do limbo corresponde às células epiteliais germinativas límbicas. Estas células são responsáveis pela manutenção das características do epitélio da córnea $^{(1)}$. Estudos experimentais e clínicos mostram que a remoção das células epiteliais germinativas resulta em crescimento epitelial conjuntival sobre a córnea (conjuntivalização), e com concomitante vascularização e inflamação ${ }^{(2-3)}$.

A demonstração de células caliciformes da conjuntiva sobre a superfície da córnea pelo exame de citologia de impressão evidencia a deficiência do limbo ${ }^{(4-5)}$. A origem conjuntival do epitélio que recobre a córnea nesses casos pode ser comprovada por coloração imunofluorescente com anticorpos monoclonais (imunohistoquímica) ${ }^{(2-3)}$ e pela detecção de células caliciformes por meio da citologia de impressão. Este método de biópsia não invasivo primeiramente descrito ${ }^{(6)} \mathrm{em} 1977$, pode ser também útil em outras 
situações que requerem o exame das células superficiais do epitélio na avaliação do olho $\operatorname{seco}^{(7)}$, metaplasia escamosa ${ }^{(8)}$, contagem de células caliciformes em casos de hipovitaminose $\mathrm{A}^{(9)}$ e avaliação da superfície ocular em usuários de lentes de contato $^{(10)}$.

Este estudo teve como objetivo analisar o padrão da citologia de impressão na superfície de córneas com suspeita de deficiência de limbo, especialmente quanto à presença de células caliciformes na região da córnea.

\section{MÉTODOS}

Um total de 65 olhos de 65 pacientes submetidos à citologia de impressão perilímbica realizadas no Laboratório de Doenças Externas Oculares do Departamento de Oftalmologia da UNIFESP foram estudados. Os pacientes avaliados apresentavam alterações de superfície ocular graves e crônicos. Os espécimes foram obtidos dos olhos afetados com suspeita clínica de deficiência límbica entre fevereiro de 2000 e fevereiro de 2002. Os pacientes que apresentavam conjuntivalização foram distribuídos em 2 grupos. O grupo I compreendeu 49 pacientes com suspeita de deficiência de células germinativas do limbo e que não tinham sido submetidos à reconstrução da superfície ocular. O grupo II englobou 16 pacientes com sinais clínicos de conjuntivalização recorrente após cirurgia para reconstrução da superfície ocular com transplante de limbo e/ ou membrana amniótica.

Quanto ao sexo, no grupo I, 33 pacientes $(67,35 \%)$ eram do sexo masculino e $16(32,65 \%)$ do sexo feminino com idade média de 45,6 \pm 17,50 anos variando de 3 a 74 anos, e do grupo II todos eram do sexo masculino e idade média 36,37 $\pm 17,68$ anos, variando de 2 a 73 anos.

Amostras da camada epitelial córneo-conjuntival para estudo pelo método de citologia de impressão foram obtidas após anestesia tópica e aplicação de papel filtro de acetato de celulose esterilizado na região perilímbica do olho com conjuntivalização. O filtro da Millipore Corporation com poro de 0,45 micra, cortado manualmente com dimensões aproximadas de $5 \mathrm{~mm}$ de largura $\mathrm{x} 7 \mathrm{~mm}$ de altura, com ápice, base e abertura lateral foi posicionado com uma pinça aplicando-se a ponta do papel (ápice) sobre a córnea, a abertura no limbo e a base sobre a conjuntiva. Após pressão por 5 segundos foi removido e imediatamente imerso em solução fixadora e posteriormente corado com ácido periódico de Schiff (PAS), hematoxilina e Papanicolaou modificado, conforme técnica padroniza$\mathrm{da}^{(11-12)}$. Cada amostra em papel filtro contendo células da superfície ocular foi analisada com microscópio óptico. Foi considerada amostra adequada para inclusão no estudo, o filtro com pelo menos $1 / 3$ de sua superfície preenchida com células epiteliais. $\mathrm{O}$ filtro foi protegido do contato com a lágrima pois quando umidecido sua adesão é prejudicada. Nos casos em que o contato com a lágrima foi inevitável a colheita das amostras foi feita com outro papel filtro seco e foi considerado como positivo o paciente com pelo menos uma amostra citológica positiva para células caliciformes na córnea.

O diagnóstico de deficiência límbica foi definido pela presença de uma ou mais células caliciformes íntegras na superfície da córnea ${ }^{(4-5)}$.

\section{RESULTADOS}

No grupo I (Tabela 1), composto de 49 pacientes sem história anterior de cirurgia de reconstrução da superfície, o diagnóstico de deficiência límbica foi detectado em 21 olhos (42,85\%). No grupo II (Tabela 2), com 16 pacientes com sinais de conjuntivalização recorrente após cirurgia para reconstrução da superfície, foi possível detectar células caliciformes na superfície da córnea em 9 pacientes $(56,25 \%)$.

Dos pacientes do grupo I com diagnóstico de deficiência límbica, 9 (18,37\%) apresentavam história de queimadura química, 5 pacientes apresentavam outra etiologia provável da falência de limbo, como síndrome de Stevens-Johnson $(n=1$, $2,04 \%)$, pterígio $(n=3,6,12 \%)$ e papiloma $(n=1,2,04 \%)$ e 7 pacientes $(14,29 \%)$ não tiveram diagnóstico definido.

Em relação à etiologia da deficiência límbica do grupo I nos pacientes com citologia negativa para células caliciformes na

\begin{tabular}{|c|c|c|c|}
\hline Etiologia provável & $\begin{array}{l}\text { Células caliciformes } \\
\text { presentes na córnea }\end{array}$ & $\begin{array}{l}\text { Células caliciformes } \\
\text { ausentes na córnea }\end{array}$ & Total \\
\hline Queimaduras térmicas & 0 & $2(4,08 \%)$ & $2(4,08 \%)$ \\
\hline Síndrome de Stevens-Johnson & $1(2,04 \%)$ & $3(6,12 \%)$ & $4(8,16 \%)$ \\
\hline Pterígio & $3(6,12 \%)$ & $4(8,16 \%)$ & $7(14,29 \%)$ \\
\hline Coloboma de íris & 0 & $1(2,04 \%)$ & $1(2,04 \%)$ \\
\hline Penfigóide ocular cicatricial & 0 & $1(2,04 \%)$ & $1(2,04 \%)$ \\
\hline Pseudopenfigóide ocular & 0 & $1(2,04 \%)$ & $1(2,04 \%)$ \\
\hline Sem diagnóstico definido & 7 (14,29\%) & $8(16,33 \%)$ & $15(30,61 \%)$ \\
\hline Total & $21(42,85 \%)$ & $28(57,15 \%)$ & $49(100 \%)$ \\
\hline
\end{tabular}




\begin{tabular}{|c|c|c|c|}
\hline Etiologia provável & $\begin{array}{l}\text { Células caliciformes } \\
\text { presentes na córnea }\end{array}$ & $\begin{array}{l}\text { Células caliciformes } \\
\text { ausentes na córnea }\end{array}$ & Total \\
\hline Queimaduras químicas & $6(37,50 \%)$ & $7(43,75 \%)$ & $13(81,25 \%)$ \\
\hline Queimaduras térmicas & $1(6,25 \%)$ & 0 & $1(6,25 \%)$ \\
\hline Síndrome de Stevens-Johnson & $1(6,25 \%)$ & 0 & $1(6,25 \%)$ \\
\hline Aniridia & $1(6,25 \%)$ & 0 & $1(6,25 \%)$ \\
\hline Total & $9(56,25 \%)$ & $7(43,75 \%)$ & $16(100 \%)$ \\
\hline
\end{tabular}

córnea incluíram-se casos de queimadura química $(\mathrm{n}=8$, $16,33 \%)$ e térmica $(n=2,4,08 \%)$, pterígio $(n=4,8,16 \%)$, síndrome de Stevens-Johnson ( $\mathrm{n}=3,6,12 \%)$, coloboma de íris $(\mathrm{n}=1$, $2,04 \%)$, pseudopenfigóide ocular $(\mathrm{n}=1,2,04 \%)$ e penfigóide ocular cicatricial $(n=1,2,04 \%)$. Oito $(16,33 \%)$ pacientes não tiveram diagnóstico clínico definido.

Conforme a tabela 2 , que representa o grupo II, nove $(56,25 \%)$ pacientes tiveram a evidência no exame de citologia de impressão da deficiência de limbo após cirurgia de reconstrução da superfície ocular. Neste grupo, um paciente $(6,25 \%)$ teve recorrência dos sinais de conjuntivalização após queimadura térmica, seis $(37,50 \%)$ após queimadura química, um paciente $(6,25 \%)$ apresentava aniridia e outro $(6,25 \%)$ síndrome de Stevens-Johnson. Não foram observadas células caliciformes na córnea em 7 (43,75\%) pacientes com sinais de conjuntivalização após cirurgia para reconstrução de superfície devido à queimadura química.

Alguns resultados da citologia de impressão mostraram características morfocelulares de metaplasia escamosa e até queratinização. Em 20 olhos $(57,14 \%)$ de um total de 35 (28 sem cirurgia e 7 com cirurgia) que tiveram citologia negativa para células caliciformes na superfície da córnea, não foram encontradas células caliciformes também na conjuntiva pesquisada. Nesses casos, além da ausência de células caliciformes, a citologia de impressão revelou células epiteliais com perda da coesão intercelular e citoplasma mais abundante em relação ao tamanho do núcleo; algumas células eram poligonais e apresentavam bordos citoplasmáticos dobrados. Por vezes observou-se cariopicnose, células anucleadas degeneradas e células epiteliais esparsas eosinofílicas queratinizadas.

Em 12 amostras com resultado citológico negativo para células caliciformes na córnea foi possível observar presença de mucina nessa região.

\section{DISCUSSÃO}

Este trabalho confirma que a deficiência das células germinativas do limbo, observada em estudos experimentais através da remoção de tecido epitelial do limbo em $\operatorname{coelhos}^{(2-3)}$, também pode ser verificada em córneas humanas, portadoras de sinais clínicos de conjuntivalização.

A suspeita clínica da deficiência límbica deve ser corretamente avaliada no pré-operatório de transplante de córnea pela freqüência com que se observa o insucesso da cirurgia em casos de deficiência límbica sem tratamento ${ }^{(13-14)}$.

De acordo com outros autores ${ }^{(13)}$, o critério diagnóstico mais confiável da deficiência de limbo é a presença de células caliciformes na superfície da córnea. A presença de uma única célula caliciforme na córnea é suficiente para a confirmação do diagnóstico clínico ${ }^{(4-5)}$, critério também considerado neste trabalho.

Considerando-se todos os pacientes incluídos em nosso estudo, observa-se uma positividade média de $49,55 \%$ para células caliciformes na córnea. A maior positividade de deficiência límbica foi no Grupo II que são casos de falência de limbo recorrente após cirurgia para reconstrução da superfície ocular com transplante de limbo e/ou membrana amniótica humana preservada com $56,25 \%$ do que no Grupo I com $42,85 \%$. Conclui-se, portanto, que embora a cirurgia proposta para tratamento de deficiência límbica seja aplicada por muitos cirurgiões, em alguns casos, esta deficiência não é totalmente corrigida por meio de uma única cirurgia ${ }^{(15)}$. A superfície ocular reconstruída deve apresentar um epitélio mais favorável para a remoção adequada de células superficiais pela citologia de impressão, o que poderia explicar neste estudo o maior número de casos de deficiência de limbo confirmados citologicamente no grupo II.

Em 35 olhos, 50,45\% (28 do grupo I e 7 do grupo II), dos pacientes com suspeita clínica de conjuntivalização não foram observadas células caliciformes na superfície da córnea, não havendo a evidência citológica da deficiência de limbo. Nossos resultados diferem do observado por outros autores ${ }^{(4)}$ provavelmente pelas diferenças de diagnósticos clínicos e de critérios diagnósticos. Tais autores ${ }^{(4)}$ obtiveram resultado citológico positivo para células caliciformes na córnea em 94 amostras de um total de $134(70,14 \%)$ analisadas retrospectivamente e obtidas num período de 10 anos, considerando-se não só a presença de células caliciformes íntegras na córnea, como também a presença de grânulos de mucina livres das células como positivo para deficiência límbica. Consideramos apenas a presença destas células íntegras, e se fosse considerada a presença destes grânulos como um achado para confirmação diagnóstica, provavelmente o diagnóstico seria confirmado em um maior número de casos. Além disso, aqueles autores ${ }^{(4)}$ usaram filtro de nitrocelulose na colheita e o usado em nossa técnica é de acetato de celulose, o que poderia implicar em diferentes quantidades de células superficiais removidas. Es- 
tudos futuros podem ser úteis na comparação da celularidade obtida com estes dois tipos de papel filtro.

Em nosso estudo, em 20 amostras $(57,14 \%)$ do grupo de 35 em que não foram encontradas células caliciformes na córnea, também não haviam células caliciformes na região de conjuntiva avaliada, devido a metaplasia escamosa. Isto representa a gravidade da alteração de superfície ocular destes casos, em que encontramos até fibrose, como outro autor ${ }^{(14)}$, e explica que se pode ter metaplasia escamosa grave e aí não mais será percebida nenhuma célula caliciforme. Acreditamos que a fibrose não permite uma adesão suficiente do papel filtro para a remoção adequada de células superficiais. A ausência de células caliciformes pode também ser esperada diante da falta de condições ambientais para a normal proliferação das mesmas. Há relatos ${ }^{(16)}$ de que superfícies de conjuntiva alterada freqüentemente são cobertas por células epiteliais com metaplasia escamosa, que inclui importante redução ou ausência da população de células caliciformes, como em casos de penfigóide ocular cicatricial, síndrome de Stevens-Johnson e ceratoconjuntivite sicca.

Além desses fatores, nem todos os sinais clínicos suspeitos de conjuntivalização foram avaliados pelo mesmo grupo com um mesmo critério de inclusão pré-determinado. A destruição na superfície ocular poderia em alguns casos não ser difusa o suficiente para causar perda total das células germinativas do limbo. A citologia de impressão pode também não ter sido sensível na detecção da deficiência límbica em todos os pacientes que apresentavam clinicamente várias fases de evolução da conjuntivalização e também a falência de limbo poderia ser incompleta ou parcial.

Em 41,67\% (n=5) das 12 amostras com resultado citológico negativo para células caliciformes na córnea e com mucina não se evidenciaram células caliciformes também na área de conjuntiva avaliada. Esta mucina, livre das células, poderia ter duas origens: a de células caliciformes presentes em regiões da conjuntiva não pesquisadas ou outra fonte secretora que não corresponda às células caliciformes. Esta hipótese é corroborada por autores ${ }^{(17-18)}$ que afirmam que o conteúdo de mucina do filme lacrimal pode não estar correlacionado à densidade de células caliciformes na conjuntiva, e nestas situações, este último é o melhor indicador de alterações da superfície ocular.

O diagnóstico clínico de deficiência de limbo e o diagnóstico laboratorial pela citologia de impressão são importantes no planejamento da reconstrução da superfície ocular, especialmente antes de um possível transplante de córnea. Em pacientes com acometimento bilateral e assimétrico, a citologia de impressão pode ser útil também para se determinar a gravidade da destruição do limbo no olho menos afetado.

\section{CONCLUSÕES}

A presença de células caliciformes na superfície da córnea detectada no exame de citologia de impressão em pacientes com conjuntivalização pode confirmar o diagnóstico de deficiência de limbo no local pesquisado, porém, a ausência destas células não exclui o diagnóstico.

\section{ABSTRACT}

Purpose: To analyze by impression cytology the presence of goblet cells on corneal surfaces with conjunctivalization. Methods: Corneal-conjunctival impression cytology was performed in 65 eyes of 65 patients who had clinical signs of conjunctivalization with or without previous ocular surgery. Patients were classified into two groups according to previous history of ocular surface reconstructive surgery associated with limbal transplantation and human amniotic membrane. In group I, 49 patients without previous ocular surgery were evaluated and in group II 16 patients were included after ocular surface reconstructive surgery with conjunctivalization recurrence. Samples were obtained in the affected eye between February 2000 and February 2002 at the UNIFESP's External Eye Disease Laboratory. Limbal deficiency was detected when one or more goblets cells were found on the corneal surface. Results: In group I one or more goblet cells were found on the corneal surface of 21 eyes $(42.85 \%)$. In group II goblet cells were found on the corneal surface of 9 patients (56.25\%). Conclusion: Presence of goblet cells on the corneal surface detected by impression cytology in patients with conjunctivalization can confirm limbal stem cell deficiency, however, its absence does not exclude the diagnosis.

Keywords: Limbus corneae/cytology; Conjunctiva/cytology; Goblet cells; Epithelial cells; Cytological techniques; Diagnostic techniques opthalmological

\section{REFER̂̂NCIAS}

1. Tseng SCG. Concept and application of limbal stem cells. Eye 1989;3(Pt 2): 141-57.

2. Chen JJY, Tseng SCG. Abnormal corneal epithelial wound healing in partial thickness removal of limbal epithelium. Invest Ophthalmol Vis Sci 1991;32: 2219-33.

3. Huang AJ, Tseng SC. Corneal epithelial wound healing in the absence of limbal epithelium. Invest Ophthalmol Vis Sci 1991;32:96-105.

4. Puangsricharern V, Tseng SC. Cytologyc evidence of corneal diseases with limbal stem cell deficiency. Ophthalmology 1995;102:1476-85.

5. Sridhar MS, Vemuganti GK, Bansal AK, Rao GN. Impression cytologyproven corneal stem cell deficiency in patients after surgeries involving the limbus. Cornea 2001;20:145-8.

6. Egbert PR, Lauber S, Maurice DM. A simple conjunctival biopsy. Am J Ophthalmol $1977 ; 84: 798-801$

7. Nelson JD, Havener VR, Cameron JD. Cellulose acetate impressions of the ocular surface: dry eye states. Arch Ophthalmol 1983;101:1869-72.

8. Tseng SC. Staging of conjunctival squamous metaplasia by impression cytology. Ophthalmology 1985;92:728-33.

9. Amedee-Manesme O, Luzeau R, Wittepen JR, Hanck A, Sommer A. Impression cytology detects subclinical vitamin A deficiency. Am J Clin Nutr 1988;47: 875-8.

10. Adar S, Kanpolat A, Sürücü S, Ucakhan OO. Conjunctival impression cytology in patients wearing contact lenses. Cornea 1997;16:289-94. 
11. Barros JN, Mascaro VLDM, Gomes JAP, Freitas D, Hofling-Lima AL. Citologia de impressão da superfície ocular: técnica de exame e coloração. Arq Bras Oftalmol 2001;64:127-31.

12. Barros JN, Mascaro VLDM, Gomes JAP, Freitas D, Hofling-Lima AL. Citologia de impressão na avaliação da superfície ocular. In: $14^{\circ}$ Congresso de Prevenção da Cegueira e Reabilitação Visual; 2000 Set 6-9, Natal, Brasil; 2000. p.53

13. Tseng SC, Chen JJ, Huang AJ. Classification of conjunctival surgeries for corneal disease based on stem cell concept. Ophtahlmol Clin North Am 1990; 3:595-610

14. Gomes JAP. Atualização no tratamento das ceratoconjuntivites cicatriciais. Arq Bras Oftalmol 2000;63:91-6.
15. Prabhasawat P, Tseng SC. Impression cytology study of epithelial phenotype of ocular surface reconstructed by preserved human amniotic membrane. Arch Ophthalmol 1997;115:1360-7.

16. Nelson JD, Wright JC. Conjunctival goblet cell densities in ocular surface disorders. Arch Ophthalmol 1984;102:1049-51.

17. Friend J, Kiorpes T, Thoft RA. Conjunctival goblet cell frequency after alkali injury is not accurately reflected by aqueous tear mucin content. Invest Ophthalmol Vis Sci 1983;24:612-8.

18. Kinoshita S, Kiorpes TC, Friend J, Thoft RA. Goblet cell density in ocular surface disease. A better indicator than tear mucin. Arch Ophtalmol $1983 ; 101: 1284-7$.

\title{
VIII Congresso Internacional de Catarata e Cirurgia Refrativa
}

\section{Centro de Convenções de Pernambuco}

\author{
OLINDA - PE
}

\section{1 a 24 de abril de 2004}

\section{PROMOÇÃO:}

Sociedade Brasileira de Catarata e Implantes Intra-oculares

Sociedade Brasileira de Cirurgia Refrativa

\section{INFORMAÇÕES:}

Tel.: (81) 3442-1940 - Tel./fax: (81) 3265-7419

e-mails: sbcii@uol.com.br ou catarata@hotlink.com.br

home pages: www.catarata-refrativa.com.br e www.sbcii.com.br 